\title{
Cartografías entre música y educación
}

Los autores de este dossier tenemos la hábil manía de no interesarnos por los mismos problemas ni coincidir-necesariamente- en las maneras (tanto teóricas como prácticas) para trabajarlos. No obstante, esa capacidad para sostenernos y alojar la multiplicidad de voces y miradas es también un rasgo que caracteriza los quehaceres de nuestra Universidad y del Instituto Superior de Música en particular.

Creemos que en esa multiplicidad -y en la incomodidad de las «disonancias»- es donde es posible que algo de la investigación y el pensamiento tengan lugar.

En esta ocasión, la Revista del Instituto Superior de Música celebra la flamante oportunidad de inaugurar un dossier destinado específicamente a temas que vinculan la música con la educación; preocupación histórica del Instituto Superior de Música que hoy redobla la apuesta con estos textos.

Todos los autores formamos parte de un grupo de investigación con un trabajo en curso que sostiene diferentes tópicos en torno al eje de la formación docente. ${ }^{1}$ En este dossier, cada grupo de autores ha tomado un recorte sobre el cual construir una serie de reflexiones.

De manera que, el lector no encontrará tanto los «avances» de una investigación, sino más bien un conjunto de preocupaciones variadas como efecto del trabajo que venimos llevando a cabo.

Fuimos convocados a producir textos como núcleos problemáticos con el afán de componer colectivamente una cartografía, tal como la definen Deleuze y Guattari en Mil Mesetas.

La noción de cartografía remite a una de las características principales del rizoma. Éste (descrito exhaustivamente como bulbos, tubérculos, mana-

1 Hacemos referencia a la investigación titulada «Prácticas docentes situadas de estudiantes del ISM. Una exploración sobre las capacidades artístico-musicales adquiridas y su potencial desarrollo". La misma se encuentra en curso en el marco del PAITI (Programa de Promoción y Apoyo a la Investigación en Temas de Interés Institucional) propiciado por la Universidad Nacional del Litoral. Dicha investigación, se centra en la formación universitaria de estudiantes (futuros Profesores de Música). 
das, ratas, madrigueras), se opone principalmente a la idea de raíz. En la raíz encontramos jerarquías, principio y fin, organizaciones lineales que responden siempre a un eje central. En el rizoma, ciertos principios o características discuten ese modo particular de organización. De allí que para Deleuze y Guattari hay libros-raiz (que pretenden dar una imagen del mundo, una "copia», un calco) y libros-rizoma (preocupados no por lo que significan, sino por aquello de su afuera con lo que funcionan, deslindan, cartografían, territorializan y desterritorializan).

La cartografía se presenta como lo contrario al calco. El calco consiste en reproducir algo que se da por hecho a partir de una estructura que sobrecodifica o un eje que soporta.

Si el mapa se opone al calco es precisamente porque está totalmente orientado a una experimentación que actúa sobre lo real [...] El mapa es abierto, conectable en todas sus dimensiones, desmontable, alterable, susceptible de recibir constantemente modificaciones. Puede ser roto, alterado, adaptarse a distintos montajes, iniciado por un individuo, un grupo, una forma social (Deleuze y Guattari, 2015: 18). ${ }^{2}$

Cartografiar consiste entonces en el trazado mismo del mapa, que no escinde a quien lo traza ni a los movimientos de territorialización y desterritorializaciones pertinentes al acto. La invitación a cartografiar no consistió para este dossier en calcar unos problemas, unas situaciones; sino "trazarlas", "territorializarlas», «hacerles lugar», «experimentar», «hacerlas funcionar».

Bajo esta idea nos dimos cita a producir escrituras que se presenten como posibles entradas o abordajes a los cruces entre música y educación. Al mismo tiempo, la invitación ofreció cierta "plasticidad» para los autores en el modo de presentar sus ideas, procurando ofrecer al lector una diversidad de temas, estilos y estéticas.

La hipótesis principal de la investigación mencionada que dio lugar a las reflexiones que presentan los textos del dossier, infiere que «al momento de realizar las instancias áulicas que se proponen en prácticas docentes, los estudian-

2 Deleuze, G. y Guattari, F. (2015). Mil mesetas. Capitalismo y esquizofrenia. Valencia: Pretextos 
tes no parecen poner en juego elementos, bienes culturales-musicales, habilidades y estrategias de enseñanza que desde la formación se les ofrece».

Esto supone una brecha entre lo que la formación les otorga y lo que los estudiantes ponen en juego al momento de las prácticas. Pero ¿̇e qué está hecha esa brecha?, ¿bajo qué supuestos se sostiene?, ¿qué elementos median en la transmisión/enseñanza que nos alertan sobre la importancia de nociones como repetición, diferencia, variación, entre otras?, ¿qué piensan y cómo dimensionan los estudiantes avanzados la existencia de dicha brecha?

Algunos de estos interrogantes nos han llevado a tomar diferentes acciones de trabajo, algunas ligadas a escuchar y analizar las representaciones que, estudiantes y docentes, nos ofrecen acerca de la formación; otras, a profundizar teóricamente sobre aspectos que parecen constituir algo de esa carencia, tales como los obstáculos epistemológicos, el peso de lo que llamamos biografía escolar o la falta de relación con las nuevas tecnologías a la hora de diseñar propuestas educativas con una impronta más contemporánea, entre otros.

Muchas de esas acciones se encuentran dando aún sus primeros pasos. No obstante, los escritos del presente dossier -recuperando algunas de las resonancias de esos problemas- pretenden ofrecer al lector una pequeña colección rizomática de temas y reflexiones que intervienen tanto en la formación docente como ante algunos elementos de la enseñanza de la música. Se presentan así, a modo de ensayos, de posibles hipótesis, de reflexiones provisorias.

Con cierta resistencia a "presentar» los textos, ponemos de relieve algunas de las preocupaciones centrales que resonaron en los acentos de nuestra lectura.

Serra y Carbonari nos proponen reflexionar sobre el papel que tiene la cuestión de la biografia escolar al interior de la formación de docentes de música.

$\mathrm{Al}$ mismo tiempo, «destapan la olla» y nos invitan a oler otros elementos que intervienen en las biografías de los futuros docentes pero que no se muestran enmarcados -necesariamente- en la formación escolar.

¿Qué papel cumplen todos aquellos intersticios que estos autores nos incitan a pensar a partir de la noción alemana de Bildung?

Leonhard y Quintana se muestran preocupadas por una formación universitaria que no ofrezca deliberada batalla a los cercos cognitivos de los estudiantes (y a veces -ellas lo dicen con más decoro-inclusive de los propios Profesores). En 
este «bélico asunto», las autoras intentan pensar algunas pistas a partir del préstamo de la noción de obstáculos epistemológicos, intentado dar detallada cuenta acerca de cómo identificar (nombrar) y comenzar a desmontar algunos escollos.

Zilli y Ferrero comparten -casi secretamente- aquella preocupación de Ana Abramowski por la cuestión del afecto en la formación. Con delicado ademán artesanal, construyen binomios conformados por la unión de verbos que (a través del poderoso hilo de un guión, parecen hacer estallar algo de lo sabido y nos obligan a mirar con otros ojos la cuestión acerca de qué hacer con una música. No se privan allí de señalar la importancia de pensar la música al compás de la vida con otros.

Omega, Porta y Vergara llevan meses discutiendo las transformaciones que los usos de ciertas tecnologías traen aparejadas para la enseñanza de la música. Reniegan un poco sobre la idea de pensar las «TIC» como meros adornos y no dejan de insistir en la potencia de considerarlas a los efectos de comprender verdaderas mutaciones en las formas en que se transmite la música (y en las que nos hacemos humanos). Invitados a intentar acotar la prolífica lista de conceptos y autores que vienen recorriendo, nos acercan amigablemente a nociones como ubicuidad e interfaz, ofreciendo elementos teóricos para pensar qué del tiempo, el espacio, el saber, y los vínculos se ven alterados en la tarea de construir propuestas de educación musical más substanciosas.

Con Sierra nos sorprendimos sobre algunas de las cosas que dicen (y piensan) los estudiantes cuando no les hacemos ninguna pregunta. Con carińoso afán estético reconstruimos algo de lo dicho en forma de postales. Estas nos sirvieron para intentar comprender nuestras propias «des-orientaciones» frente a las palabras de los entrevistados. Esperamos que sirvan como soporte para discutir y desnaturalizar algunas cuestiones postergadas en la formación docente especializada en música.

Esperando que el carácter inaugural de este dossier encuentre algo de su afuera con lo que hacer rizoma, deseamos que viaje, agite, sacuda, haga cantar, trace nuevas conversaciones, favorezca interlocuciones y -principalmenteintervenga en aquello que solemos llamar «la realidad».

Pablo Lang, editor invitado 